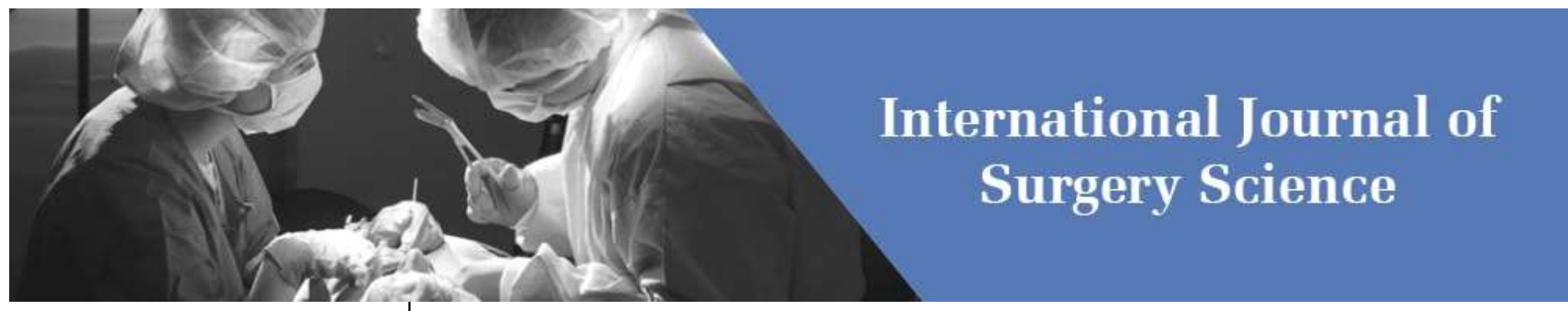

E-ISSN: 2616-3470

P-ISSN: 2616-3462

(C) Surgery Science

www.surgeryscience.com

2021; 5(1): 332-334

Received: 17-12-2020

Accepted: 05-02-2021

\section{Dr. Amutha}

Professor, Department of General

Surgery, Sree Mookambika

Institute of Medical Sciences.

Kulashekharam, Tamil Nadu,

India

Dr. S Rajkumar

Professor, Department of General

Surgery, Sree Mookambika

Institute of Medical Sciences.

Kulashekharam, Tamil Nadu,

India

\section{Dr. Anandra}

Junior Resident, Department of

General Surgery, Sree Mookambika

Institute of Medical Sciences.

Kulashekharam, Tamil Nadu,

India

\section{Dr. Indran GP Nair}

Junior Resident, Department of General Surgery, Sree Mookambika Institute of Medical Sciences.

Kulashekharam, Tamil Nadu, India

\section{A comparative study of chemical sphincterotomy (using 2\% diltiazem) and lateral internal sphincterotomy for chronic anal fissure}

\author{
Dr. Amutha, Dr. S Rajkumar, Dr. Anandraj and Dr. Indran GP Nair
}

DOI: https://doi.org/10.33545/surgery.2021.v5.i1f.631

\section{Abstract}

Background: Anal fissure is the most common painful condition of anal region characterised by vertical ulcers affecting distal end of anal canal. The main aim of this study is comparing $2 \%$ diltiazem and lateral internal sphincterotomy in the treatment of chronic anal fissure.

Materials and Methods: The Study was conducted as a clinical trial in Sree Mookambika institute of medical sciences, Kulasekharam from May 2020 to November 2020.100 patients diagnosed with chronic fissure in ano on the basis of history of painful defecation with or without per rectal bleeding for more than 6 weeks and per rectal examination were enrolled in the study after obtaining an informed written consent from them. Results has been detailed in both descripted and statistical point of view and simplified in understandable format.

Results: In $89.36 \%$ of patients in diltiazem group and $100 \%$ of patients in lateral internal sphincterotomy group fissure healed completely between 4-8 weeks. In the diltiazem group pain relief was good. 42 patients $(89.4 \%)$ had pain relief at the end of 14 weeks. 5 patients $(10.6 \%)$ had no pain relief. But pain relief in lateral internal sphincterotomy group was excellent with $100 \%$ patients having complete pain relief by 8 weeks' time. Mild headache was experienced with diltiazem by $3(6.4 \%)$ patients. 1 patient $(2.1 \%)$ complained of flatus incontinence with lateral internal sphincterotomy.

Conclusion: We conclude that lateral internal sphincterotomy is the gold standard treatment of chronic fissure in ano but chemical sphincterotomy using $2 \%$ diltiazem gel can be considered as a good second line treatment option in those unfit for surgery or for those not willing for surgery.

Keywords: Anal fissure, lateral internal sphincterotomy, chemical sphincterotomy, diltiazem

\section{Introduction}

Anal fissure is defined as linear ulceration of the squamous lining of the distal anal canal. It is more common that producing symptoms like pain on defecation constipation, bleeding per anum and pruritus ${ }^{[1,2]}$. Etiopathogenesis of fissure in ano is persistent hypertonia of the anal sphincter attributed by passage of hard stools, dietary irregularities, forceful passage of foreign body causing trauma and in females traumatic delivery is the most important cause ${ }^{[3]}$. Therefore main aim of the treatment is to relieve the spasm of internal anal sphincter with medical and surgical method. Though Lateral internal sphincterotomy is the gold standard treatment with $95 \%$ clearance rate it has remarkable risk of impaired anal incontinence ${ }^{[4]}$.

\section{Materials and methods}

The study was conducted in Sree Mookambika institute of medical sciences, Kulasekharam from May 2020 to November 2020.100 patients diagnosed with chronic fissure in ano on the basis of history of painful defecation with or without per rectal bleeding for more than 6 weeks and per rectal examination were enrolled in the study after obtaining an informed written consent from them. Results has been detailed in both descripted and statistical point of view and simplified in understandable format.

\section{Results}

In our study most of the cases belonged to age group 21-30 years (figure 1) with slight male preponderance (figure 2). It was noted that $100 \%$ patients, both males and females had painful defecation which was followed by constipation, bleeding per anum, local pruritis and discharge
Dr. Amutha

Professor, Department of General

Surgery, Sree Mookambika

Institute of Medical Sciences.

Kulashekharam, Tamil Nadu,

India 
per anus (figure 3). Majority of the fissures were posterior in location with sentinel pile present in $78 \%$ of the patients. Cases were followed up at 2,4,6,8,14 weeks and 6 months for fissures healing, pain alleviation, side effects and recurrences. Three patients from group A and 2 patients from group B were lost to follow up and hence not included in statistical analysis. In $89.36 \%$ of patients in Group A and $100 \%$ of patients in group B fissure healed completely between 4-8 weeks. In the group A, who underwent treatment with $2 \%$ Diltiazem organo gel pain relief was good. 42 patients $(89.4 \%)$ had pain relief at the end of 14weeks. 5 patients $(10.6 \%)$ had no pain relief. But the pain relief in group B patients, who underwent lateral internal sphincterotomy, pain relief was excellent with $100 \%$ patients having complete pain relief by 8 weeks' time (figure 4). Mild headache was experienced by $3(6.4 \%)$ patients in group A (Diltiazem group). In group B, 1 patient $(2.1 \%)$ complained of flatus incontinence and none in group A.1 patient $(2.1 \%)$ in the diltiazem group had recurrence which was subsequently managed by lateral internal sphincterotomy and fissure healed in 4 weeks after surgery. There was no recurrence in lateral internal sphincterotomy group. (10.6\%) had no pain relief. But the pain relief in group B patients, who underwent lateral internal sphincterotomy, pain relief was excellent with $100 \%$ patient.

\section{Discussion}

Anal fissure is the linear ulceration of the squamous lining of the distal anal canal producing symptoms like pain on defecation, bleeding per rectum and pruritus ${ }^{[5]}$. It is most commonly seen in middle aged people with no sexual preponderance ${ }^{[6]}$. In our study most affected age group was $21-30$ with slight male preponderance.

Anal fissures can occur in posterior midline, anterior midline or both commonest being in posterior midline because of lack of muscular support of anal canal epithelium posteriorly and poor blood support posteriorly ${ }^{[7]}$. In our study also posterior midline was the most common position affecting $92 \%$ of patients.

The Etiopathogenesis of fissure in ano is hypertonicity of internal anal sphincter ${ }^{[8]}$. Hence treatment like dilatation and internal anal sphincterotomy is aimed at reducing resting anal pressure and thereby treating the condition ${ }^{[9]}$. Anal fissures are divided into two types acute and chronic ${ }^{[10]}$. Anal fissures become chronic when they persist beyond 6 weeks and do not heal with dietary modifiers and stool softeners ${ }^{[11]}$

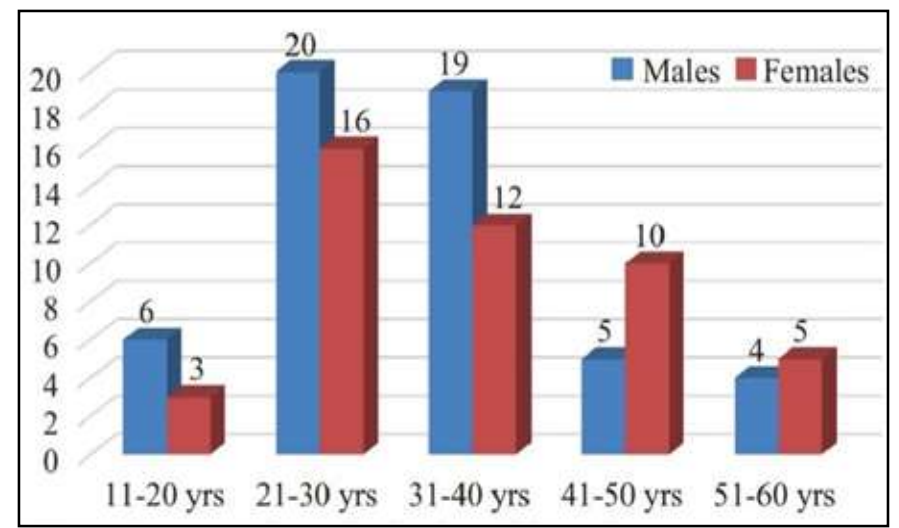

Fig 1: Age and sex distribution

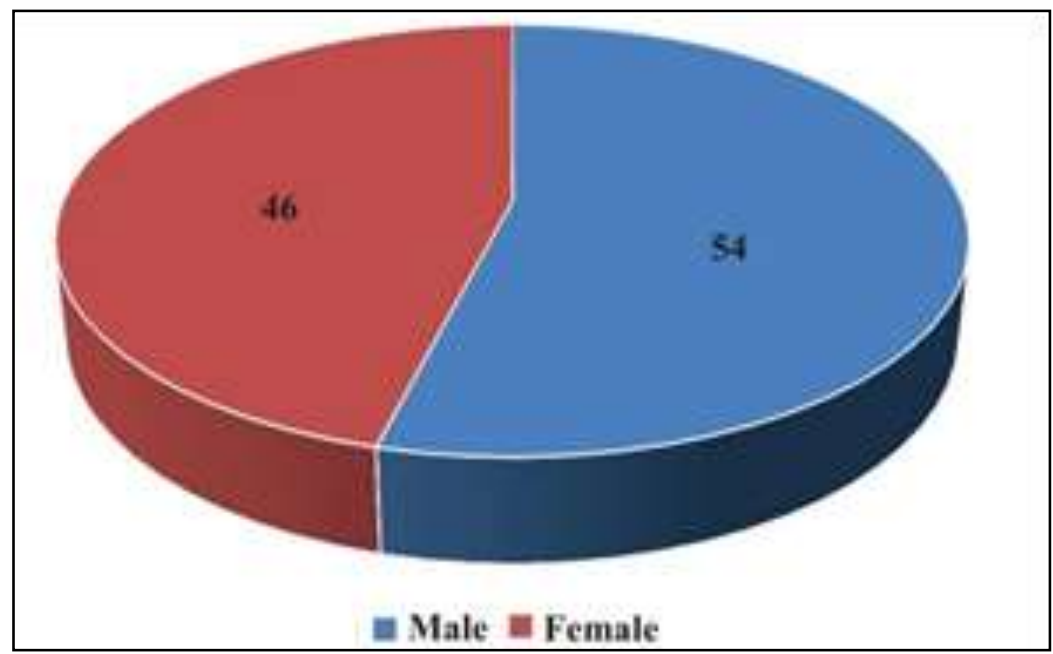

Fig 2: Sex distribution

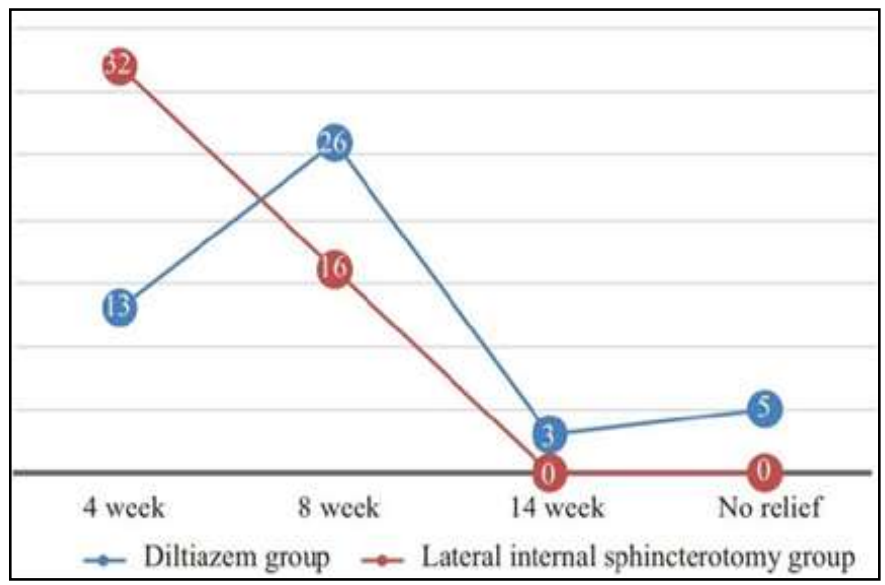

Fig 3: Pain relief in Diltiazem and lateral internal sphincterotomy group

\section{Conclusion}

From the present study we conclude that Lateral internal sphincterotomy is the gold standard in treating chronic anal fissure while topical $2 \%$ diltiazem gel can be considered as a optimal second line treatment in those patients who are unfit for surgery and for those patients who are not willing for surgery.

Funding: No funding sources

\section{Conflict of interest: Nil}

\section{References}

1. Leong APK. The pharmacological treatment of anal fissures - A future role in the primary care. Singapore Med J 2003;44:136-37.

2. Jensen SL. Diet and other risk factors for fissure-in-ano. A 
prospective case control study. Dis Colon Rectum 1988;31:770-73.

3. Peter J Lunniss. The anus and anal canal, Norman S. Williams, Christopher J.K. Bulstrode and P. Roman O'Connell. Bailey and Love's Short Practice of Surgery, Hodder Arnold, 25th edition 2008, 1251-1253.

4. Gupta PJ. The treatment of fissure in ano- revisited. Afr Health Sci 2004;4:58-62.

5. Golfam F, Golfam P, Khalaj A, Mortaz S SS. The effect of topical nifedipine in the treatment of chronic anal fissures. Acta Medica Iranica 2010;48:295-99.

6. Jonathan NL, John HS. A randomised, prospective, doubleblind, placebo-controlled trial of glyceryl trinitrate ointment in the treatment of anal fissures. The Lancet 1997;349:1114.

7. Garcea G, Sutton C, Mansoori S, Lloyd T, Thomas M. The results following conservative lateral sphincterotomy for treatment of chronic anal fissures. Colorectal Disease 2003;5:311-14.

8. Dhawan S, Chopra S. Nonsurgical approaches for the treatment of anal fissures. The American Journal of Gastroenterology 2007;102:1312-21.

9. Jonas Marion, Schole field JH. Taylor I, Johnson CD. Recent advances in Surgery. 24th Edition. Churchill Livingstone. Anal fissure and chemical sphincterotomy 2001; p. 115.

10. Goligher J. Anal Fissure. In: John Goligher, Surgery of the Anus, Rectum and Colon; 5th Edition; AITBS 1992, PP: 150.

11. Jennifer $\mathrm{K}$ Lowney, James $\mathrm{W}$ Fleshman Jr. Benign disorders of the ano rectum, Michael J. Zinner and Stanley W. Ashley. Maingot's Abdominal Operations, Tata McGraw Hill, 11th edition 2007, 680-684. 